\title{
Effect of High-Fat Diet upon Inflammatory Markers and Aortic Stiffening in Mice
}

\author{
Andre Bento Chaves Santana, ${ }^{1}$ Thais Cristina de Souza Oliveira, ${ }^{1}$ Barbara Lobo Bianconi, ${ }^{1}$ \\ Valerio Garrone Barauna, ${ }^{2}$ Ed Wilson Cavalcante Oliveira Santos, ${ }^{3}$ Tatiana P. Alves, ${ }^{1}$ \\ Juliane Cristina S. Silva, ${ }^{1}$ Patricia Fiorino, ${ }^{4}$ Primavera Borelli, ${ }^{3}$ \\ Maria Claudia Costa Irigoyen, ${ }^{2}$ José Eduardo Krieger, ${ }^{2}$ and Silvia Lacchini ${ }^{1}$
}

${ }^{1}$ Institute of Biomedical Sciences, University of Sao Paulo, 05508-000 Sao Paulo, SP, Brazil

${ }^{2}$ Heart Institute, University of Sao Paulo Medical School, 05403-900 Sao Paulo, SP, Brazil

${ }^{3}$ Faculty of Pharmaceutical Sciences, University of Sao Paulo, 05508-000 Sao Paulo, SP, Brazil

${ }^{4}$ Health, Biology and Science Center, Mackenzie University, 01302-907 Sao Paulo, SP, Brazil

Correspondence should be addressed to Silvia Lacchini; lacchini@icb.usp.br

Received 25 November 2013; Revised 17 March 2014; Accepted 20 March 2014; Published 11 June 2014

Academic Editor: Senthil K. Venugopal

Copyright (C) 2014 Andre Bento Chaves Santana et al. This is an open access article distributed under the Creative Commons Attribution License, which permits unrestricted use, distribution, and reproduction in any medium, provided the original work is properly cited.

\begin{abstract}
Changes in lifestyle such as increase in high-fat food consumption are an important cause for vascular diseases. The present study aimed to investigate the involvement of ACE and TGF- $\beta$ in the aorta stiffness induced by high-fat diet. C57BL/6 male mice were divided in two groups according to their diet for 8 weeks: standard diet (ST) and high-fat diet (HF). At the end of the protocol, body weight gain, adipose tissue content, serum lipids and glucose levels, and aorta morphometric and biochemical measurements were performed. Analysis of collagen fibers by picrosirius staining of aorta slices showed that HF diet promoted increase of thin (55\%) and thick $(100 \%)$ collagen fibers deposition and concomitant disorganization of these fibers orientations in the aorta vascular wall (50\%). To unravel the mechanism involved, myeloperoxidase (MPO) and angiotensin I converting enzyme (ACE) were evaluated by protein expression and enzyme activity. HF diet increased MPO (90\%) and ACE (28\%) activities, as well as protein expression of ACE. TGF- $\beta$ was also increased in aorta tissue of HF diet mice after 8 weeks. Altogether, we have observed that the HF diet-induced aortic stiffening may be associated with increased oxidative stress damage and activation of the RAS in vascular tissue.
\end{abstract}

\section{Introduction}

Aortic disease is an important cause of mortality worldwide, which may be exemplified by vascular aneurysm, atherosclerotic lesion, and vascular stiffening [1]. Lifestyle characteristics such as obesity promote adverse effects on the vascular system by increasing aortic stiffness [2].

Increased collagen deposition leads to stiffening of the arterial wall, compromising vascular distensibility and contributing to a feedback of the hypertensive process [3]. The tunica adventitia (the outmost layer of the vessels) is composed of connective tissue whose main matrix component is collagen fibers. Some lamellae of elastic fibers can also be found in this network [4]. The outer layers of the tunica adventitia are rich in collagen types I and III which are produced by local fibroblasts [5]. In light microscopy, these layers are not distinct but integrate with the connective tissue around the outside of the vessel, helping it to maintain its vascular structure. The deposition of collagen has a functional role in the adventitia maintaining, strengthening the vessel wall to prevent its rupture. Collagen is abundantly deposited in extracellular matrix (ECM) acting in maintaining the integrity and resistance of vascular wall [6].

Arterial stiffening involves mechanisms of ECM remodeling, promoted by increased collagen deposition, and this mechanism involves both endothelial cells from intima and 
fibroblasts from adventitia layer. Macrophages, neutrophils, $\mathrm{T}$ cells, and adipocytes can also induce arterial stiffness by paracrine stimuli [7]. Oxidative stress can also promote aortic stiffness, resulting in remodeling of the vascular wall [8]. Some studies have showed that during the processes of aorta stiffening in hypertensive patients the renin-angiotensin system may be overactivated [9].

The renin-angiotensin system (RAS) is described as a cascade of biochemical reactions whose activity is essential for cardiovascular homeostasis. Angiotensin II (Ang II) is a main effector of the RAS acting on homeostasis and cardiovascular function, through the type 1 (AT1) and type 2 (AT2) receptors [10]. Angiotensin I (Ang I) is converted to Ang II by the action of angiotensin I-converting enzyme (ACE) expressed mainly in the pulmonary vascular endothelium. The local RAS may act on the vasculature independently of systemic RAS [11].

Ang II at the vascular wall is capable to induce the tunica intima hyperplasia regardless of hemodynamic or neurohumoral factors [11-13]. The development of vascular pathologies such as atherogenesis, hypertension, and restenosis is the result of trophic stimulation of the vessel wall, primarily promoted by the action of Ang II, leading to structural modifications in vascular ECM $[11,12,14]$.

In addition, Ang II stimulates the activation of several genes that lead to changes in vascular function, including matrix metalloproteinases (MMPs), monocyte chemoattractant protein 1 (MCP-1), vascular cell adhesion molecule (VCAM), vascular endothelial growth factor (VEGF) and plasminogen activator inhibitor-1 (PAI-1), interleukins, tumor necrosis factor alpha (TNF- $\alpha$ ), and transforming growth factor beta (TGF- $\beta$ ) [15]. The TGF- $\beta$ is a multifunctional protein, participating in the regulation of cell division, differentiation, migration, cell adhesion, extracellular matrix production, and others, involved in several pathologies, including cardiovascular diseases [16].

Perivascular tissue can exert paracrine actions though the release of proinflammatory agents as interleukin-6 (IL-6) and TNF- $\alpha$ produced by adipose tissue. Perivascular adipose tissue (PVAT) also expresses components of RAS such as ACE and produces Ang II, contributing to autocrine and paracrine actions in inflammatory responses [17, 18].

In this context, the increased consumption of lipids can promote major changes in arterial tissue, especially through activation of the RAS, the induction of oxidative stress, and proinflammatory factors. In this way, it can induce structural changes in conductance vessels and constitute a risk for developing cardiovascular diseases. Thus, it is of great importance to understand the effects that the highfat diet (HF) has on the aorta. Furthermore, it is essential to identify markers related to the processes of stiffening of conductance vessels caused by high-fat diet. Moreover, there are known the effects of lipid overload on RAS components and its relationship with local mechanisms of inflammatory sites by the action of TGF- $\beta$. Thus, the present study aimed to investigate the causal effect of high-fat diet upon vascular inflammatory markers and its relationship to aortic stiffness.

\section{Methods}

2.1. Animals. Twenty-six C57BL/6J male mice ( 8 weeks old) from the Animal House of the Department of Anatomy, Institute of Biomedical Sciences/University of São Paulo (ICB/USP), were used. The animals were kept in a room with light/dark cycle of 12 hours and controlled temperature between 22 and $24^{\circ} \mathrm{C}$, with feed and water given ad libitum. This study was approved by Institutional Ethics Committee on the Use of Animals (CEUA-ICB/USP).

Mice were randomized into 2 groups following their diet for 8 weeks: (1) standard diet (ST, $n=10$ ) [19] and (2) high-fat diet [20] (HF, $n=16)$. Animals were weighed weekly, and at the end of the eight weeks, the animals were subjected to sixhour fasting before blood withdrawals for serum glucose and lipid profile analyses. After that, adipose tissue was quantified; heart rate and blood pressure were measured previously to blood and tissue collections.

2.2. Quantification of Adipose Tissue. X-ray images were captured for quantification of adipose tissue in each group by In-Vivo Imaging System FX PRO in Center for Research Facilities (CEFAP) - ICB/USP. The images obtained were used in measurements of adipose tissue from each animal using the software Image (version $1.32 \mathrm{j}$, from $\mathrm{NIH}$ ) and ICY (version 1.3.6.0, from http://www.bioimageanalysis.org/). The percentage of visceral adipose tissue content was obtained by measuring periepididymal and retroperitoneal cushions relative to the body image of each animal.

2.3. Heart Rate and Systolic Blood Pressure Measures. Heart rate (HR) and systolic blood pressure (SBP) were obtained using a tail-cuff plethysmography (Kent Scientific) coupled to an analogic-to-digital converter. HR and SBO signals were analysed by using BP-2000 Blood Pressure Analysis program. All mice were adapted to the system for three days before measurements. Measurements were conducted for two days, using at least 10 correct measures in each day, for each mouse.

2.4. Blood and Tissue Collections. At the end of the protocol, mice were anesthetized with a lethal intraperitoneal dose of ketamine $(180 \mathrm{mg} / \mathrm{Kg})$ and xylazine $(20 \mathrm{mg} / \mathrm{kg})$. Blood sample and aorta tissue were harvested and stored in ultrafreezer for later analysis. Tissue collection procedures for biochemical measurements were different from those for histological study. For immunoblotting and enzyme activity assays, mice were perfused with $0.9 \% \mathrm{NaCl}$ solution and thoracic aorta was harvested and immediately frozen in liquid nitrogen. For histological and immunostaining assays, mice received heparin (50 U per animal, together with anesthesia) and were perfused with $0.9 \% \mathrm{NaCl}$ solution at constant pressure (80$90 \mathrm{mmHg}$ ) followed by buffered $4 \%$ formalin solution. The aortae were postfixed in $4 \%$ buffered formalin for 24-48 hours. Tissues were processed and paraffin-embedded for histological evaluation.

2.5. Serum Glucose, Cholesterol, HDL, LDL, and Triglycerides. Serum glucose, cholesterol, HDL, LDL, and triglyceride levels 
were measured by spectrophotometer according to the procedures described in commercially available kits (Labtest).

2.6. Angiotensin Converting Enzyme Activity Assay. ACE activity in aortae extracts was determined using Abz-FRK (Dnp)P-OH derivatives as substrates by continuously measuring the fluorescence according to our previous publications [21, 22]. Tissue samples were quickly harvested, homogenized in Tris- $\mathrm{HCl}$ buffer, $\mathrm{pH} 7.0$, containing $50 \mathrm{mM}$ $\mathrm{NaCl}$, and centrifuged at $1,000 \mathrm{~g}$ for $10 \mathrm{~min}$. The assays were performed at $37^{\circ} \mathrm{C}$ in $0.1 \mathrm{M}$ Tris- $\mathrm{HCl}$ buffer, $\mathrm{pH} 7.0$, containing $50 \mathrm{mM} \mathrm{NaCl}$ and $10 \mathrm{mM} \mathrm{ZnCl}$. Hydrolysis rate of the intramoleculary quenched fluorogenic substrate AbzYRK-(Dnp)p $(10 \mathrm{mM})$ incubated with aliquots of tissues homogenate and serum for $30 \mathrm{~min}$ at $37^{\circ} \mathrm{C}$ was assessed to obtain ACE enzymatic activity. Fluorescence increments along the time were read at $420 \mathrm{~nm}$ emission: $320 \mathrm{~nm}$ excitation. Tissue ACE activity was expressed as fluorescence units (AFU) $\cdot \mathrm{min}^{-1} \cdot \mathrm{mg}^{-1}$ of protein $[21,22]$. The protein content was determined by the Bradford method by using bovine serum albumin as the standard (Bio-Rad protein assay).

2.7. Myeloperoxidase Enzyme Activity Assay. The myeloperoxidase (MPO) enzyme activity was measured by continuous recording using the reagent Amplex Ultrared. The enzyme activity was measured continuously every 1 minute in a fluorometer by fluorescence emission at $530 \mathrm{~nm}$ wavelengths emission and $590 \mathrm{~nm}$ excitation. Approximately $50 \mu \mathrm{L}$ of supernatant for each sample was incubated with $50 \mu \mathrm{L}$ of substrate Amplex. The enzymatic activity measurement of MPO was performed by using as inhibitor sodium azide $(10 \mu \mathrm{M})$. The MPO activity was expressed as fluorescence units (AFU) $\cdot \mathrm{min}^{-1} \cdot \mathrm{mg}^{-1}$ of protein. All assays were performed in duplicate.

2.8. Immunoblotting Analysis. Aortae were lysed in RIPA buffer ( $1 \mathrm{mM}$ EDTA, $1 \mathrm{mM}$ EGTA, $2 \mathrm{mM} \mathrm{MgCl}_{2}, 5 \mathrm{mM} \mathrm{KCl}$, $25 \mathrm{mM}$ Hepes, $\mathrm{pH}$ 7.5, $2 \mathrm{mM}$ DTT, $1 \mathrm{mM}$ PMSF, $0.1 \%$ Triton $\mathrm{X}-100$, and $1: 100$ cocktail of protease inhibitors) and stirred for 30 minutes at $4^{\circ} \mathrm{C}$. The homogenates were centrifuged at $10000 \times \mathrm{g}$ for $10 \mathrm{~min}$ at $4^{\circ} \mathrm{C}$. After that, the supernatant was collected. Tissue lysate $(50 \mu \mathrm{g})$ was heated in sample buffer (200 mM Tris-HCl, pH 6.8, 40\% glycerol, $8 \%$ sodium dodecyl sulphate, $0.1 \%$ DDT, and $0.4 \%$ bromophenol blue) at $100^{\circ} \mathrm{C}$ for 5 minutes. Next, the samples were subjected to sodium dodecyl sulfate polyacrylamide gel electrophoresis (SDS-PAGE) using the Mini-PROTEAN Tetra Cell (Bio-Rad). After electrophoresis, the gel proteins were transferred to nitrocellulose membrane Hybond-C Extra (GE Healthcare) in transfer medium $(0.025 \mathrm{M}$ Tris, $0.192 \mathrm{M}$ glycine, $0.1 \% \mathrm{SDS}$, and $20 \%$ methanol) using the system Trans-Blot SD Semi-Dry Transfer Cell (Bio-Rad). The membranes were washed in a solution of 1X TBS-T three times (5 minutes each wash). Next, the membranes were blocked with $5 \%$ bovine serum albumin (BSA) for 3 hours, then washed three times in TBS-T, and then incubated overnight with antibody anti-ACE (anti-ACE goat polyclonal C-20, SC-12187, Santa Cruz Biotechnology, Inc.) in 1: 500 dilution, antibody anti-TGF- $\beta$ (anti-TGF-beta 1 rabbit polyclonal SC-146, Santa Cruz Biotechnology, Inc.) in 1:500 dilution, and anti $\beta$-tubulin (anti- $\beta$-tubulin, Santa Cruz sc-9104) in 1:1000 dilution. Membranes were exposed in ECL WB Detection Reagents (GE Healthcare) and revealed in Image Quant LAS 4000 mini (GE Healthcare) equipment. Protein bands were quantified by optical densitometry using ImageJ software (version 1.32j, NIH).

2.9. Histological Preparation of Aortae Sections. The aortae maintained in buffered $4 \%$ formalin for $24-48 \mathrm{~h}$ to complete the fixation process were processed and paraplast (Fisher Brand) embedded for histological evaluation. Descending thoracic aorta cross slices were obtained using a microtome (Microm HM200 ERGOSTAR) with $5 \mu \mathrm{m}$ thickness. Three to five slices for each animal were placed on each slide.

2.10. Immunostaining Assays. Immunohistochemistry (IHC) was performed using the $\mathrm{ABC}$ (streptavidin-biotin-peroxidase) method and used the following antibodies: ACE (SC12187, Santa Cruz Biotechnology, Inc., 1:500 dilution) and TGF- $\beta$ (SC-146, Santa Cruz Biotechnology, Inc., 1:500 dilution). Antigen retrieval was performed using citrate buffer $\mathrm{pH} 6.0$ for TGF- $\beta$ unmasking. The blocking of endogenous peroxidase was done with $3 \% \mathrm{H}_{2} \mathrm{O}_{2}$ solution and incubation of the slices for 30 minutes at room temperature. Histological sections of the aorta were incubated at $4^{\circ} \mathrm{C}$ with primary antibodies diluted in blocking solution ( $3 \%$ bovine serum albumin in PBS) for a minimum of 18 hours (overnight). Afterwards, incubation was performed with secondary antibody conjugated with biotin and streptavidin conjugated with horseradish peroxidase (HRP). Then, 3,3-diaminobenzidine (DAB) was used as chromogen. Counterstaining was performed with hematoxylin. Negative control reactions were prepared omitting the primary antibody in one slice for each aorta.

2.11. Morphometric Analysis. Morphometric measurements and collagen fibers analysis were performed on picrosiriusstained tissues. The cross-sections from aortae were viewed in microscope (Axio Imager.A2, Zeiss), and the images were digitized by computer image analysis system (AxioVision release 4.8.2 SP2).

In morphometric measurements, intima, media, and adventitia areas were calculated. All measurements were performed using ImageJ program. In these analyses, three slices were examined in each animal, obtained in three distinct sections of the thoracic aorta. The intima area was obtained from the difference between the area inside the inner elastic lamina and the luminal area. The media area was obtained from the difference between the area inside the outer elastic lamina and the area inside the inner elastic lamina. Lastly, the adventitia area was obtained from the difference between the area around of the adventitia and the area inside the outer elastic lamina. Values obtained were expressed as the ratio between adventitia/media area and the ratio between media/intima area. 
2.12. Quantification of Collagen Fibers. Evaluation of collagen fibers was performed in cross-sections from the aorta by use of polarized light. This analysis aims to assess the deposition of thin and thick fibers of collagen in the extracellular matrix and assess how these fibers are arranged in the vessel due to the high fat diet. The study of molecular distribution of collagen fibers was made in picrosirius-stained sections. Therefore picrosirius-polarization method is specific for collagenous structures and enhances their birefringence quality [23]. This characteristic permits, under polarized light, the observation of thin collagen fibers with weak birefringence in green color. Already thick collagen fibers are composed of bundles of highly birefringent fibers presented with orange or red color [24].

The quantification of aortic collagen fibers was performed in three distinct sections of the aorta, by using ICY program and the plugin KMeans Color Quantization. Values obtained were expressed in the graph from the area of thick and thin collagen fibers in adventitia. In these analyses, three $5 \mu \mathrm{m}$ slices were examined per animal for each aortic slice.

2.13. Measurement of the Waviness of Collagen Fibers. The analysis of the waviness of the collagen fibers in polarized light was performed by program ImageJ using the Orientation $J$ plugin $[25,26]$. The quantification of waviness was made to verify the degree of disorganization of collagen fibers, measuring the entropy of each region of interest (ROI) marked in the micrograph. Again, three slices were examined per animal, always considering the same relative position of image in the vessel. For each segment of collagen at 400x magnification five entropy measures were performed. In each section of the aorta four distinct segments in cross-section were analyzed. Values obtained were expressed in graph from the percentage of entropy.

2.14. Statistical Analysis. Experimental values are evaluated as mean \pm standard deviation. The results are statistically evaluated by comparing the groups by unpaired $t$-test with Welch correction. The test was used to determine if there were differences in the phenomena observed between the groups ST versus HF. For all analyses the significance level of $P \leq$ 0.05 was assumed.

\section{Results}

3.1. Effects of High-Fat Diet on Body Weight (BW), Adipose Tissue Content, Heart Rate (HR), Systolic Blood Pressure (SBP), and Lipid and Glucose Levels. HF diet induced greater body weight gain compared with mice in ST diet after 8 weeks (Table 1). HF diet group increased the BW by $12 \%$ compared to the beginning of the protocol while no significant weight gain was observed in the ST group.

Adipose tissue content was analyzed by X-ray imaging system. The increase in periepididymal and retroperitoneal adipose tissues in the HF diet group can be noticed from the representative image (Figure 1). Quantification of body fat mass at the end of 8 weeks of diet showed significant difference between groups, with total adipose tissue mass

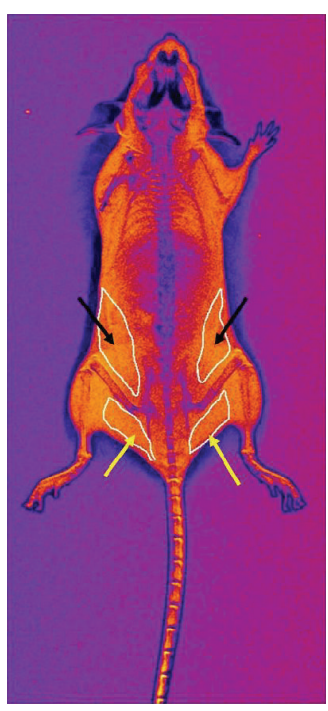

(a)

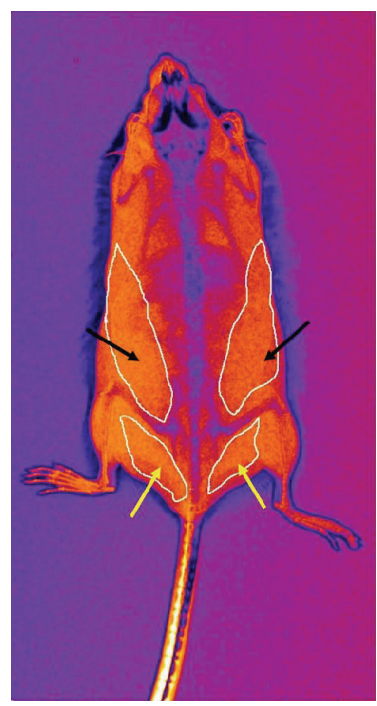

(b)
FIGURE 1: X-ray imaging with filter for viewing adipose tissue (marked in white). Black arrows show the retroperitoneal cushions of adipose tissue. Yellow arrows show the periepididymal cushions of adipose tissue. (a) ST diet mice; (b) HF diet mice.

increased in HF diet group (Table 1). These data demonstrate the efficiency of HF diet to promote fat gain in wild-type mice. Also, serum lipid profile showed significantly increased levels of total cholesterol, LDL, and glucose in HF diet group when compared to the ST diet group (Table 1). Differences were not observed in serum HDL and VLDL between groups. Heart rate was not different among groups while systolic blood pressure decreased in HF diet group compared to the ST diet group (Table 1).

3.2. HF Diet Induces Structural Adaptation in Aorta. Morphometric analyses of thoracic aorta segments showed significant difference in the tunica adventitia/tunica media area ratio after the 8 -week protocol (ST diet, $1.16 \pm 0.04$ versus HF diet, $1.57 \pm 0.09 ; P<0.001$; Figure 2(a)). However, difference was not found in the tunica media/tunica intima area ratio (ST diet, $1.24 \pm 0.02$ versus HF diet, $1.25 \pm 0.04$, Figure 2(b)). Picrosirius staining of aorta slices showed an increase in collagen deposition in the tunica adventitia of HF diet group (Figure 3(a)). Under polarized light it was observed that the total collagen content increase was due to a twofold increase in thick fibers (ST, $11630 \pm 4489 \mu \mathrm{m}^{2}$ versus HF, $23519 \pm 6033 \mu \mathrm{m}^{2} ; P<0.01$; red staining) and a 1.5fold increase in thin fibers (ST, $18155 \pm 2737 \mu \mathrm{m}^{2}$ versus HF, $28209 \pm 6587 \mu \mathrm{m}^{2} ; P<0.01$; green staining) in HF diet group compared to ST diet group (Figures 3(a) and 3(b)).

Waviness quantification of collagen fibers (Figure 4(a)) in the tunica adventitia showed a significant increase in entropy of fibers disposition in HF diet group. The average entropy of fibers of the ST diet group was $18.4 \pm 7.7 \%$, while the HF diet group obtained $41.4 \pm 11.4 \%$ (Figures 4 (b) and $4(\mathrm{c})$ ). 
TABLE 1: Body weight, percentage of adipose tissue, systolic blood pressure, heart rate, HDL, LDL, VLDL cholesterol, and serum glucose levels of mice maintained on different diets.

\begin{tabular}{lcr}
\hline & ST diet & HF diet \\
\hline Body weight $(\mathrm{g})$ & & $23.5 \pm 1.8(n=16)$ \\
$\quad$ First week & $23.1 \pm 1.3(n=10)$ & $35.1 \pm 4.1^{*}(n=16)$ \\
$\quad$ Eighth week & $30.6 \pm 3.2(n=10)$ & $28.33 \pm 5.8^{*}(n=10)$ \\
Adipose tissue (\%) & $16.95 \pm 1.7(n=5)$ & $624 \pm 50(n=16)$ \\
Heart rate (bpm) & $609 \pm 39(n=9)$ & $103.8 \pm 5.2^{*}(n=16)$ \\
Systolic blood pressure (mmHg) & $117.5 \pm 10.9(n=9)$ & $58.8 \pm 9.3(n=7)$ \\
HDL $(\mathrm{mg} / \mathrm{dL})$ & $42.4 \pm 7.3(n=7)$ & $112.9 \pm 24.3^{*}(n=7)$ \\
LDL $(\mathrm{mg} / \mathrm{dL})$ & $86.37 \pm 17.9(n=7)$ & $11.3 \pm 2.3(n=7)$ \\
VLDL $(\mathrm{mg} / \mathrm{dL})$ & $12.7 \pm 1.6(n=7)$ & $182.9 \pm 32.0^{*}(n=7)$ \\
Cholesterol (mg/dL) & $141.5 \pm 23.2(n=7)$ & $372.0 \pm 53.5^{*}(n=7)$ \\
Glucose $(\mathrm{mg} / \mathrm{dL})$ & $170.2 \pm 17.6(n=7)$ & \\
\hline
\end{tabular}

${ }^{*} P \leq 0.05$.

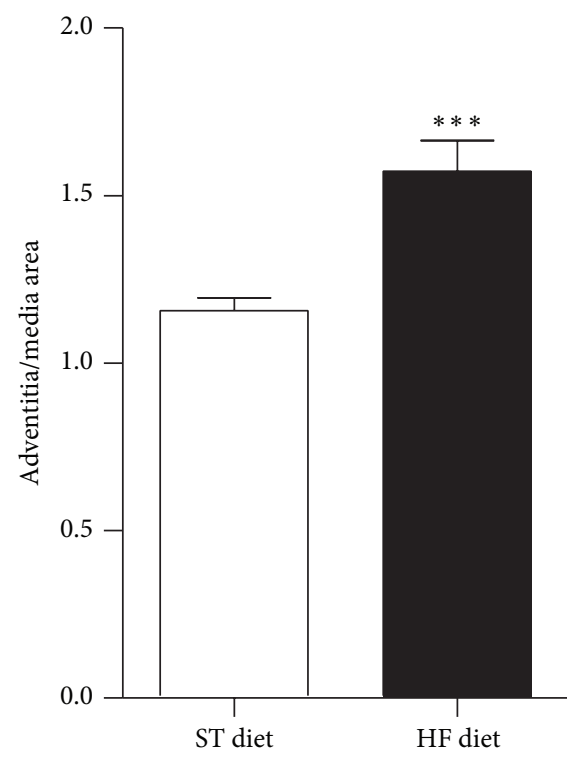

(a)

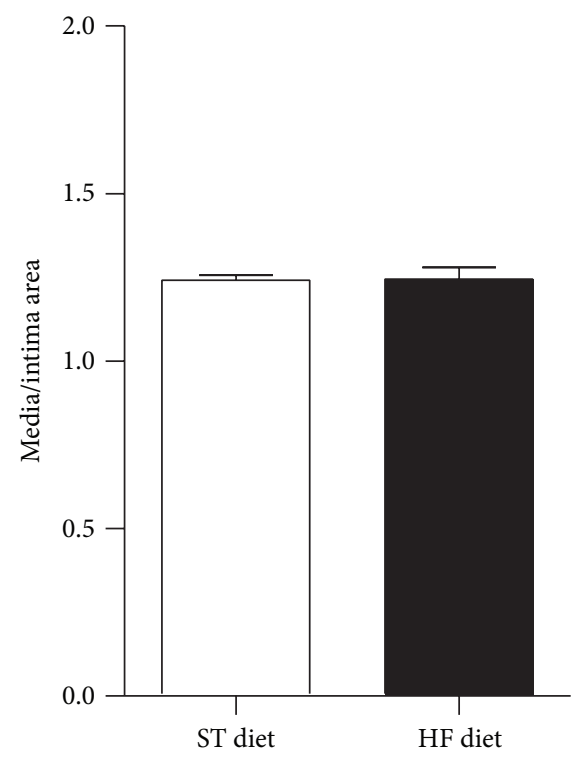

(b)

FIgURE 2: Morphometric analyses of aorta sections. Adventitia area/media area (a); media/intima area (b). ${ }^{* * *} P \leq 0.001 ; n=5$ per group.

3.3. Aortic ACE and MPO Activity after High-Fat Diet. HF diet increased MPO activity by $90 \%$ (ST, $0.0929 \pm 0.0342$ versus $\mathrm{HF}, 0.1770 \pm 0.0500 \mu \mathrm{F} \cdot \mathrm{min}^{-1} \cdot \mu \mathrm{g}^{-1}, \quad P<0.01$, Figure 5(a)) and ACE activity by $28 \%$ (ST, 759.9 \pm 101.2 versus $\mathrm{HF}, 978.2 \pm 168.3 \mu \mathrm{F} \cdot \mathrm{min}^{-1} \cdot \mu \mathrm{g}^{-1}$, Figure $\left.5(\mathrm{~b})\right)$.

ACE protein expression analyzed by immunoblotting was also increased by $26.5 \%$ after 8 weeks of HF diet (Figure 6(a)). Immunostaining of aortae slices showed higher ACE signal in intima, media, and perivascular adipose tissue in the HF diet group (Figure 6(c)).

3.4. Increased TGF- $\beta$ Expression in HF Diet Group. Aortic TGF- $\beta$ protein expression in HF diet group was also increased compared to the ST diet group (Figures 7(a)-7(c)).
By immunoblotting, the HF diet group showed an increase of $36.5 \%$ compared to the ST diet group. By immunostaining aorta slices, TGF- $\beta$ showed intense staining in the intima, media, and also perivascular adipose tissue (Figure $7(\mathrm{c})$ ).

\section{Discussion}

The results of the present study reveal that both local RAS and proinflammatory markers such as MPO and TGF- $\beta$ may be related to the vascular structural changes induced by the high-fat diet for 8 weeks in wild-type mice.

Images obtained by X-ray scanning showed a greater accumulation of adipose tissue in animals fed the highfat diet compared to the control group. Accumulation of 


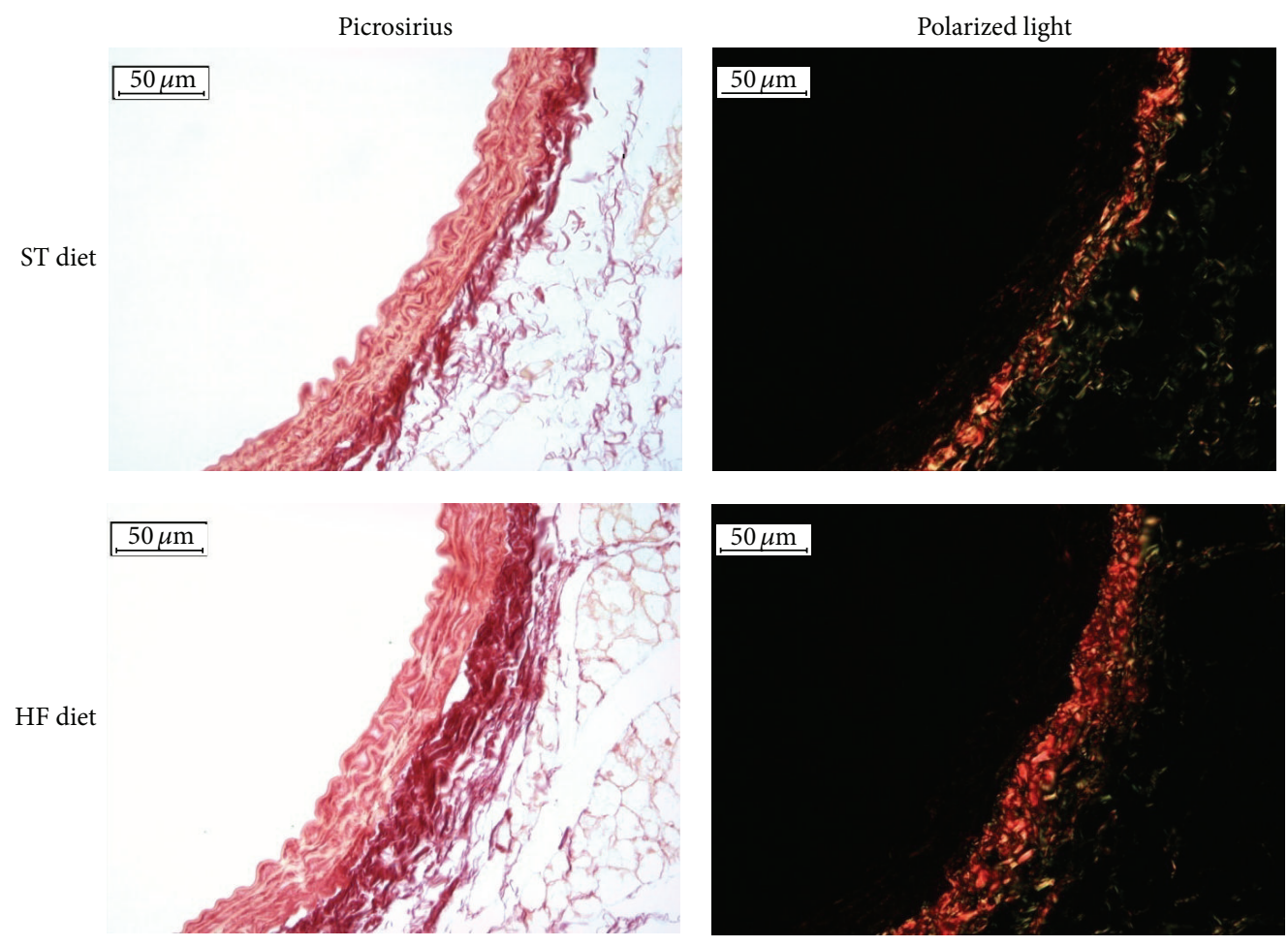

(a)

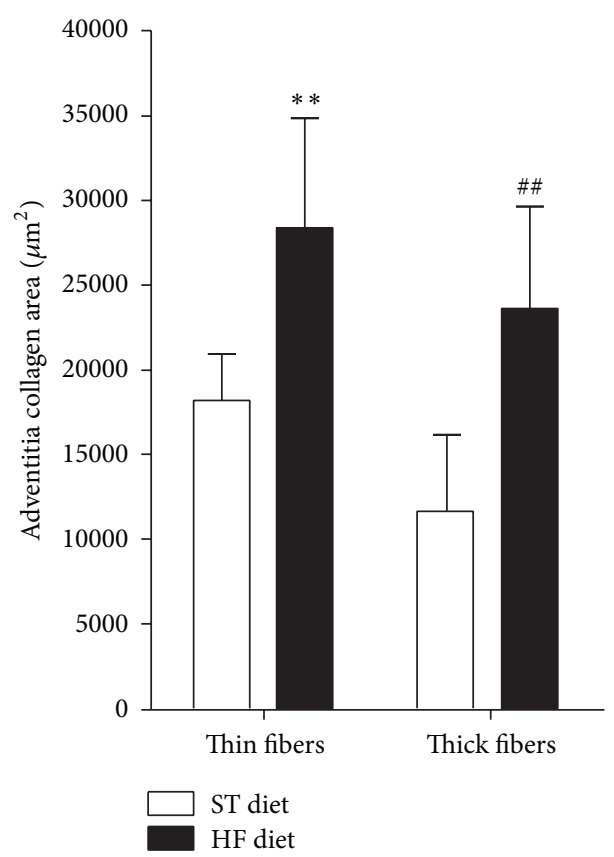

(b)

Figure 3: Collagen content in aortae. Representative photomicrographs of mouse aorta under picrosirius staining-light microscopy and polarized light microscopy, magnification of $400 \mathrm{x}$ (a). Quantitative analyses of the collagen fibers in adventitia from the HF diet and ST diet groups (b). ${ }^{* *} P \leq 0.01 ;{ }^{\#} P \leq 0.01$; HF diet versus ST diet; $n=5$ per group. 


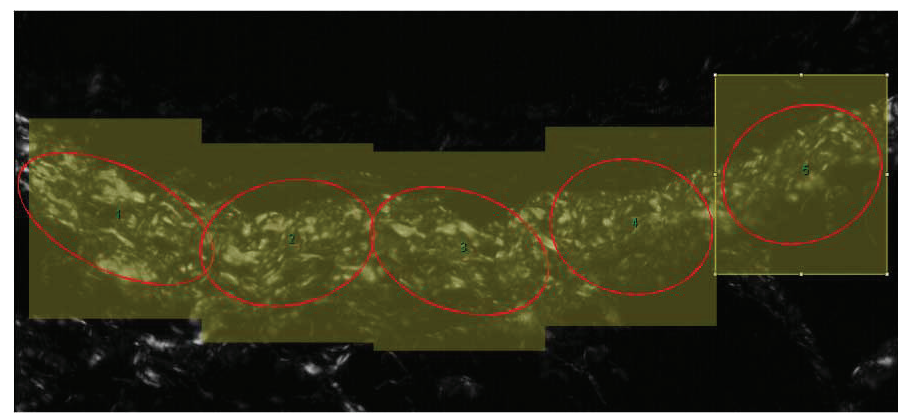

(a)

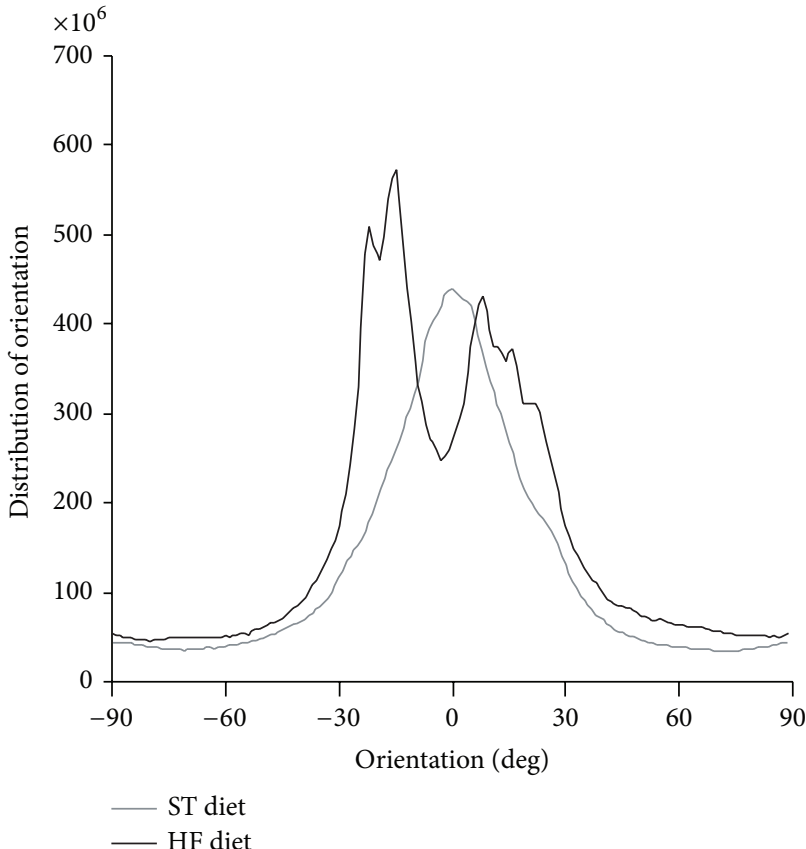

(b)

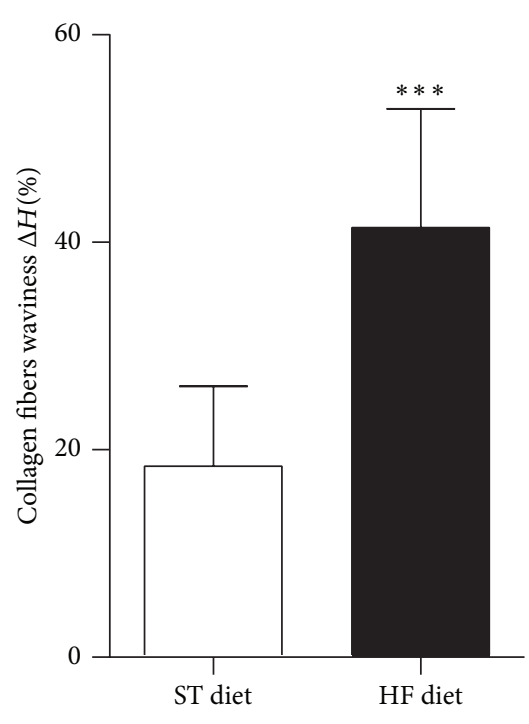

(c)

FIGURE 4: Quantitative analyses of collagen fibers orientation and waviness. Representative image of waviness quantifications of collagen fibers in the tunica adventitia performed using the ImageJ. Photomicrograph at 400 times magnification under polarized light (a). The overall fibers orientation represented as a normalized histogram (b). Waviness analysis showed increased disorientation of collagen fibers in the tunica adventitia of the aortas of mice maintained on HF diet (c). $\Delta H$ is the entropy of the fibers; ${ }^{* * *} P \leq 0.001 ; n=5$ per group.

retroperitoneal and epididymal fat in mice is equivalent to visceral adipose tissue of human obesity $[27,28]$. The type of consumed lipid can modify the accumulation of adipose tissue. There is a high correlation between the percentage of body fat and percentage of saturated fat and monounsaturated fat intake by diet.

The increased consumption of high-fat diet, associated with decreased physical activity and endocrine disorders and genetic and metabolic effect may have a role in the development of obesity. These processes can influence the metabolism of fatty acids, as well as inducing an increase of adipose tissue accumulation and production of proinflammatory cytokines, among other humoral factors [29]. The elevation of serum LDL cholesterol is accompanied by excess of visceral adipose tissue and contributes to increasing the risk of developing dyslipidemia [30].
In this study, we have verified an increase in the tunica adventitia/tunica media area ratio, suggesting a possible increase in perivascular collagen deposition. Under polarized light microscopy an increase in both thick and thin collagen fibers in mice subjected to high-fat diet was confirmed. In addition, the evaluation of collagen fibers waviness showed an increase of entropy, suggesting not only an increase of collagen fibers deposition but also a loss of parallel fibrillar distribution, leading to a possible increase in the distribution network of collagen fibers and a consequent increase in the resistance of vascular wall, as recently reported [31]. This increase of vascular wall resistance may be the starting trigger to the arterial stiffening process.

Several mechanisms may be related to arterial stiffening in obesity, including hypertension, oxidative stress, growth factors, and inflammation. Interestingly, the group 


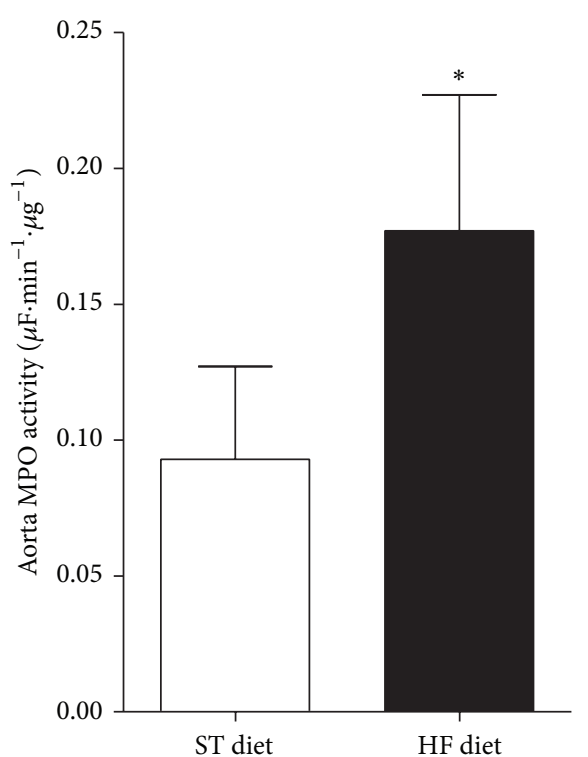

(a)

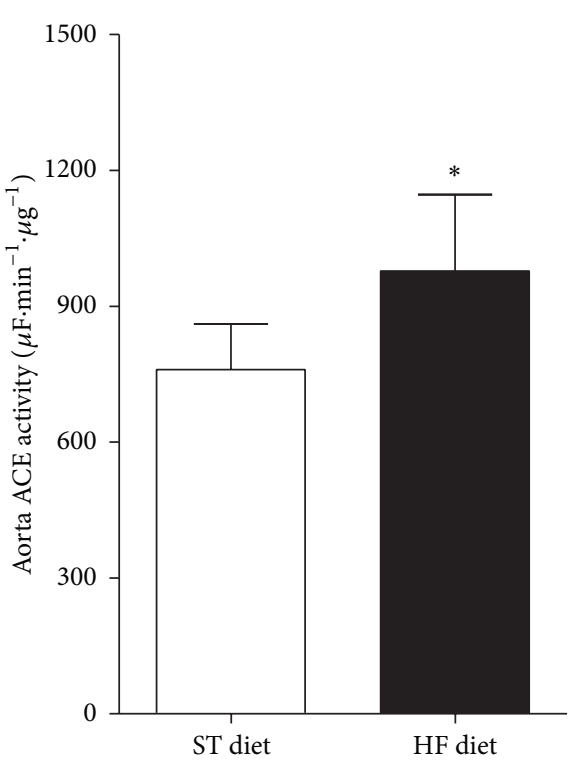

(b)

FIGURE 5: Myeloperoxidase (MPO, (a)) and angiotensin I converting enzyme (ACE, (b)) activities in aortic tissue. ${ }^{*} P \leq 0.05 ; n=6$ per group.

that received high-fat diet did not develop hypertension. In contrast, these mice showed a reduction of blood pressure. This reduction in blood pressure may be due to the metabolic modifications, where the group which received high-fat diet developed hyperlipidemia and hyperglycemia. In this context, the reduction of blood pressure in rats and mice with diabetes mellitus was already described [32].

Regarding the role of oxidative stress, growth factors, and inflammation, we have evaluated the myeloperoxidase activity as a marker of leukocyte activity. It has already been shown that the increase of MPO activity in aortae of highfat diet mice is an important indicator of local oxidative stress mediated by leukocytes triggered by accumulation of lipids [33]. In fact, our study demonstrated increase of aortic MPO activity in high-fat diet group. It is well described that oxidative stress contributes to important changes in vascular function, especially in endothelial reactivity and injuries caused by dyslipidemia [34]. It is important to note that a certain degree of peroxidation is important to eliminate the accumulation of LDL in vascular wall by monocyte activity [35].

Hyperglycemia, hyperlipidemia, and oxidative stress lead to endothelial activation and an increase of other proteins involved in inflammation and growth cell. In this case, ACE and TGF- $\beta$ are important mechanisms leading to cellular growth, inflammation, and extracellular matrix deposition. It was verified that patients with visceral obesity present high levels of free fatty acids, which promote the development of diabetes and endothelial dysfunction [36, 37]. Also, polymorphonuclear and mononuclear cells are capable of producing Ang II through the action of free fatty acids to promote insulin resistance and endothelial dysfunction [38].
Considering that high-fat diet could promote substantial changes in RAS activity, this study verified an increase of ACE expression and activity in aorta of high-fat diet mice. Increased enzymatic activity of ACE in aorta suggests an increase of angiotensin II production that is able to induce collagen synthesis in vascular smooth muscle cells via AT1 receptor and stimulate the release of TGF- $\beta[39,40]$. In addition, Ang II has a role in the remodeling of the ECM increasing collagen synthesis and deposition and reducing its degradation [41].

Positive staining for ACE in aorta by immunostaining was observed mainly in tunica intima and perivascular adipose tissue of high-fat diet mice group. These data indicate that vascular RAS may be capable of starting and maintaining proinflammatory processes, since the production of angiotensin II can act not only on vascular tone but also in inflammatory responses. This inflammatory response could lead to cell proliferation and activation of immune cells such as monocytes.

TGF- $\beta$ plays an important role in vascular remodeling processes, with an important role in profibrotic responses [16]. By immunostaining assays, an intense staining of TGF$\beta$ in mice aorta submitted to high-fat diet was observed. This technique permits us to verify that TGF- $\beta$ was found not only in the intima and media layers, but also in adventitia and perivascular multilocular adipose tissue.

The increased deposition of collagen fibers in the tunica adventitia of mice aortae subjected to a high-fat diet is evident in histological evaluations. The high waviness degree of collagen fibers in the aortic tunica adventitia promoted by high-fat diet is another point of structural change that may be directly or indirectly mediated by local RAS, oxidative 


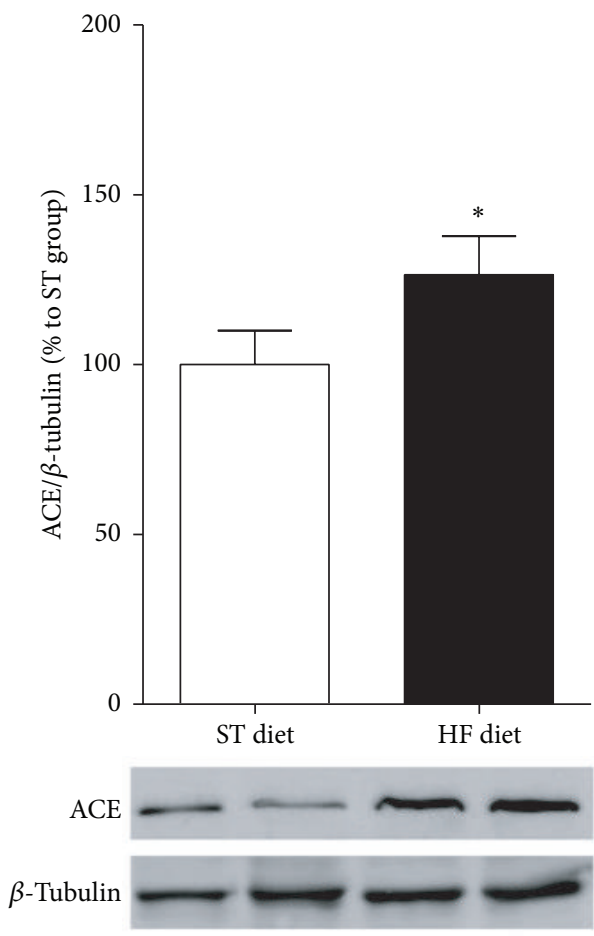

(a)

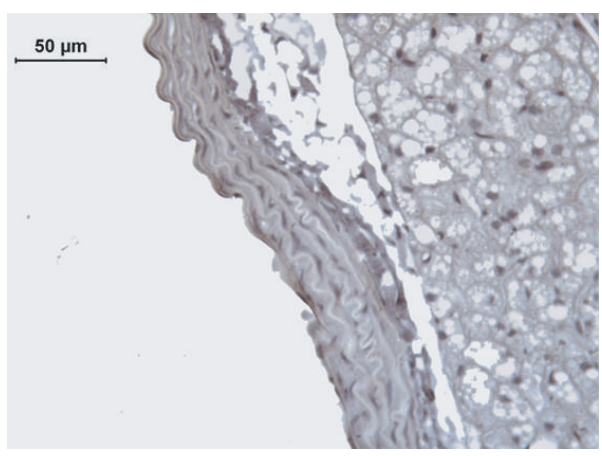

(b)

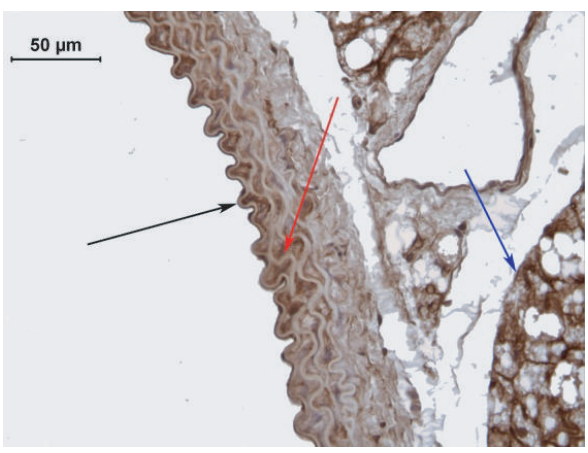

(c)

FIGURE 6: ACE expression analyses by immunoblotting (a) and immunostaining in aortae (ST diet (b) and HF diet (c)). ACE expression was normalized by $\beta$-tubulin expression. In (c), black arrow indicates ACE expression in tunica intima; red arrow indicates ACE expression in tunica media; blue arrow indicates ACE expression in perivascular adipose tissue. ${ }^{*} P \leq 0.05 ; n=8$ per group.

stress, or TGF- $\beta$ activity. Thus, these data show that highfat diet was able to induce stiffness of vascular aorta wall through the increase in deposition and disorganization of thick collagen fibers. The extracellular matrix remodeling depends on three key factors, such as hemodynamic changes and humoral factors triggering the synthesis, release, and activation of substances that can influence the growth, death, or cell migration (release of TGF- $\beta$ ), and structural changes in vascular wall. Thus, our results support the idea that aortic stiffness in response to high-fat diet may be dependent on oxidative stress and proinflammatory mechanisms involving RAS.

\section{Conclusions}

This study showed that the stiffness of aortic wall induced by high fat diet involves an increase of deposition and disorganization of collagen fibers in tunica adventitia. This structural change of collagen fibers disposition is accompanied mainly by an increased activity and protein expression of ACE at tunica intima and perivascular adipose tissue. Moreover, the increases of TGF- $\beta$ in the intima, adventitia, and perivascular adipose tissue, associated with the elevation of myeloperoxidase activity, suggest that an inflammatory process, associated with oxidative stress, is even a profibrotic stimulus for the collagen deposition and vascular stiffening. 


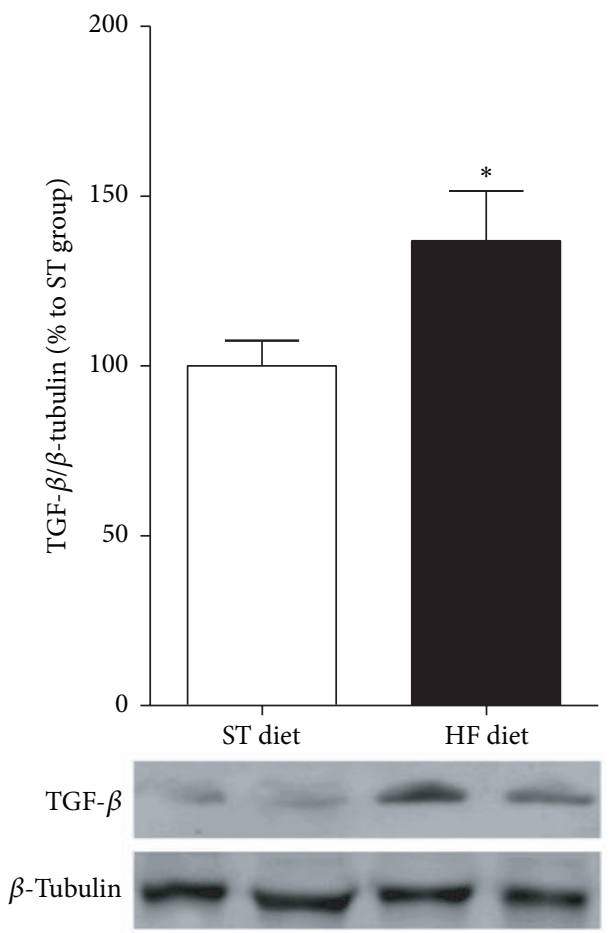

(a)

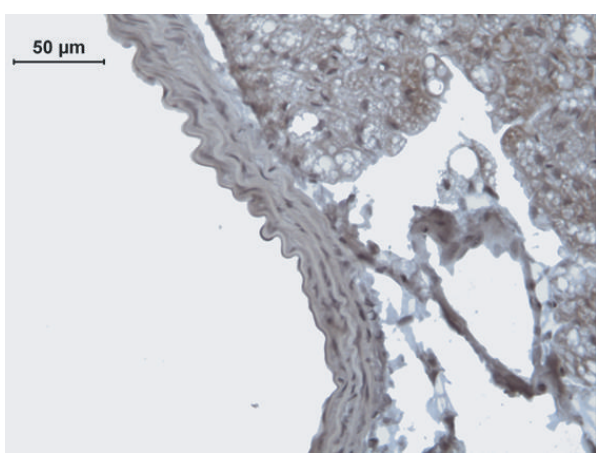

(b)

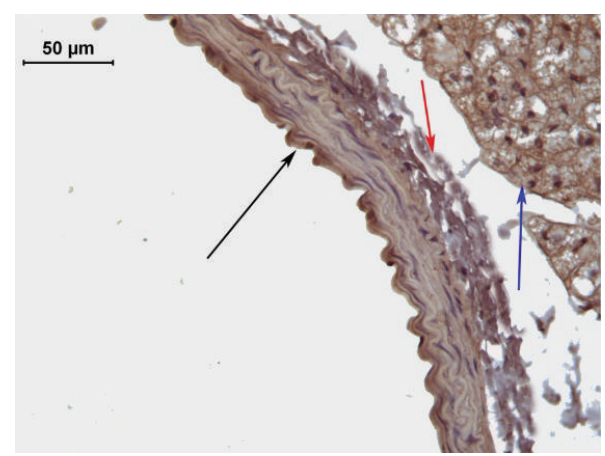

(c)

FIGURE 7: TGF- $\beta$ expression analyses by immunoblotting (a) and immunostaining in aortae (ST diet (b) and HF diet (c)). TGF- $\beta$ expression was normalized by $\beta$-tubulin expression. TGF- $\beta$ expression was normalized by $\beta$-tubulin expression. In (c), black arrow indicates TGF- $\beta$ expression in tunica intima; red arrow indicates TGF- $\beta$ expression in tunica adventitia; blue arrow indicates ACE expression in perivascular adipose tissue. ${ }^{*} P \leq 0.05, n=8$ per group.

\section{Conflict of Interests}

The authors declare that there is no conflict of interests regarding the publication of this paper.

\section{References}

[1] A. Tsamis, J. T. Krawiec, and D. A. Vorp, "Elastin and collagen fibre microstructure of the human aorta in ageing and disease: a review," Journal of the Royal Society Interface, vol. 10, no. 83, Article ID 20121004, 2013.

[2] J.-Y. Chen, P.-J. Tsai, H.-C. Tai et al., "Increased aortic stiffness and attenuated lysyl oxidase activity in obesity," Arteriosclerosis, Thrombosis, and Vascular Biology, vol. 33, no. 4, pp. 839-846, 2013.
[3] D. J. Campbell, J. B. Somaratne, A. J. Jenkins et al., "Impact of type 2 diabetes and the metabolic syndrome on myocardial structure and microvasculature of men with coronary artery disease," Cardiovascular Diabetology, vol. 10, article 80, 2011.

[4] K. R. Stenmark, M. E. Yeager, K. C. El Kasmi et al., "The adventitia: essential regulator of vascular wall structure and function," Annual Review of Physiology, vol. 75, pp. 23-47, 2013.

[5] T.-H. Lan, X.-Q. Huang, and H.-M. Tan, "Vascular fibrosis in atherosclerosis," Cardiovascular Pathology, vol. 22, no. 5, pp. 401-407, 2013.

[6] F. T. Bosman and I. Stamenkovic, "Functional structure and composition of the extracellular matrix," Journal of Pathology, vol. 200, no. 4, pp. 423-428, 2003.

[7] J. A. Leopold, "Cellular and molecular mechanisms of arterial stiffness associated with obesity," Hypertension, 2013. 
[8] R.-H. Zhou, A. E. Vendrov, I. Tchivilev et al., "Mitochondrial oxidative stress in aortic stiffening with age the role of smooth muscle cell function," Arteriosclerosis, Thrombosis, and Vascular Biology, vol. 32, no. 3, pp. 745-755, 2012.

[9] A. Benetos, J. Topouchian, S. Ricard et al., "Influence of angiotensin II type 1 receptor polymorphism on aortic stiffness in never-treated hypertensive patients," Hypertension, vol. 26, no. 1, pp. 44-47, 1995.

[10] F. Fyhrquist and O. Saijonmaa, "Renin-angiotensin system revisited," Journal of Internal Medicine, vol. 264, no. 3, pp. 224236, 2008.

[11] A. J. Naftilan, "Role of the tissue renin-angiotensin system in vascular remodeling and smooth muscle cell growth," Current Opinion in Nephrology and Hypertension, vol. 3, no. 2, pp. 218227, 1994.

[12] R. Ross, "Atherosclerosis - an inflammatory disease," New England Journal of Medicine, vol. 340, no. 2, pp. 115-126, 1999.

[13] A. R. Aroor, V. G. DeMarco, G. Jia et al., "The role of tissue renin-angiotensin-aldosterone system in the development of endothelial dysfunction and arterial stiffness," Frontiers in Endocrinology, vol. 4, article 161, 2013.

[14] M. J. Mulvany, "Effects of angiotensin converting enzyme inhibition on vascular remodelling of resistance vessels in hypertensive patients," Journal of Hypertension, vol. 14, no. 6, pp. S21-S24, 1996.

[15] V. J. Dzau and M. Lopez-Ilasaca, "Searching for transcriptional regulators of Ang II-induced vascular pathology," Journal of Clinical Investigation, vol. 115, no. 9, pp. 2319-2322, 2005.

[16] M. Ruiz-Ortega, J. Rodríguez-Vita, E. Sanchez-Lopez, G. Carvajal, and J. Egido, "TGF- $\beta$ signaling in vascular fibrosis," Cardiovascular Research, vol. 74, no. 2, pp. 196-206, 2007.

[17] A. Nguyen Dinh Cat and R. M. Touyz, "A new look at the reninangiotensin system - focusing on the vascular system," Peptides, vol. 32, no. 10, pp. 2141-2150, 2011.

[18] H. Kawahito, H. Yamada, D. Irie et al., "Periaortic adipose tissue-specific activation of the renin-angiotensin system contributes to atherosclerosis development in uninephrectomized apoE ${ }^{-/-}$mice," American Journal of Physiology. Heart and Circulatory Physiology, vol. 305, no. 5, pp. H667-H675, 2013.

[19] P. S. Jacob, T. M. de Meneses Fujii, M. Yamada et al., "Isocaloric intake of a high-fat diet promotes insulin resistance and inflammation in Wistar rats," Cell Biochemistry and Function, vol. 31, no. 3, pp. 244-253, 2013.

[20] P. G. Reeves, F. H. Nielsen, and G. C. Fahey Jr., "AIN-93 purified diets for laboratory rodents: final report of the American Institute of Nutrition ad hoc writing committee on the reformulation of the AIN-76A rodent diet," Journal of Nutrition, vol. 123, no. 11, pp. 1939-1951, 1993.

[21] F. S. Zamo, V. G. Barauna, S. Chiavegatto, M. C. Irigoyen, and E. M. Oliveira, "The renin-angiotensin system is modulated by swimming training depending on the age of spontaneously hypertensive rats," Life Sciences, vol. 89, no. 3-4, pp. 93-99, 2011.

[22] S. Lacchini, A. S. Heimann, F. S. Evangelista, L. Cardoso, G. J. J. Silva, and J. E. Krieger, "Cuff-induced vascular intima thickening is influenced by titration of the Ace gene in mice," Physiological Genomics, vol. 37, no. 3, pp. 225-230, 2009.

[23] G. S. Montes and L. C. Junqueira, "The use of the Picrosiriuspolarization method for the study of the biopathology of collagen," Memorias do Instituto Oswaldo Cruz, vol. 86, supplement, pp. 1-11, 1991.
[24] L. M. G. de Macedo Braga, S. Lacchini, B. D. Schaan et al., "In situ delivery of bone marrow cells and mesenchymal stem cells improves cardiovascular function in hypertensive rats submitted to myocardial infarction," Journal of Biomedical Science, vol. 15, no. 3, pp. 365-374, 2008.

[25] J. Griffin, R. Delgado-Rivera, S. Meiners, and K. E. Uhrich, "Salicylic acid-derived poly(anhydride-ester) electrospun fibers designed for regenerating the peripheral nervous system," Journal of Biomedical Materials Research A, vol. 97, no. 3, pp. 230-242, 2011.

[26] A. J. Schriefl, M. J. Collins, D. M. Pierce, G. A. Holzapfel, L. E. Niklason, and J. D. Humphrey, "Remodeling of intramural thrombus and collagen in an Ang-II infusion ApoE-/-model of dissecting aortic aneurysms," Thrombosis Research, vol. 130, no. 3, pp. e139-e146, 2012.

[27] D. Estadella, L. M. Oyama, A. R. Dâmaso, E. B. Ribeiro, and C. M. Oller Do Nascimento, "Effect of palatable hyperlipidic diet on lipid metabolism of sedentary and exercised rats," Nutrition, vol. 20, no. 2, pp. 218-224, 2004.

[28] M. H. G. Gaíva, R. C. Couto, L. M. Oyama et al., "Polyunsaturated fatty acid-rich diets: effect on adipose tissue metabolism in rats," British Journal of Nutrition, vol. 86, no. 3, pp. 371-377, 2001.

[29] M. A. de Carvalho-Filho, J. B. C. Carvalheira, L. A. Velloso, and M. J. A. Saad, "Insulin and angiotensin II signaling pathways cross-talk: implications with the association between diabetes mellitus, arterial hypertension and cardiovascular disease," Arquivos Brasileiros de Endocrinologia e Metabologia, vol. 51, no. 2, pp. 195-203, 2007.

[30] B. Klop, J. W. F. Elte, and M. C. Cabezas, "Dyslipidemia in obesity: mechanisms and potential targets," Nutrients, vol. 5, no. 4, pp. 1218-1240, 2013.

[31] M. R. Hill, X. Duan, G. A. Gibson, S. Watkins, and A. M. Robertson, "A theoretical and non-destructive experimental approach for direct inclusion of measured collagen orientation and recruitment into mechanical models of the artery wall," Journal of Biomechanics, vol. 45, no. 5, pp. 762-771, 2012.

[32] K. de Angelis, B. D. Schaan, C. Y. Maeda, P. Dall'Ago, R. B. Wichi, and M. C. Irigoyen, "Cardiovascular control in experimental diabetes," Brazilian Journal of Medical and Biological Research, vol. 35, no. 9, pp. 1091-1100, 2002.

[33] R. Zhang, M.-L. Brennan, Z. Shen et al., "Myeloperoxidase functions as a major enzymatic catalyst for initiation of lipid peroxidation at sites of inflammation," Journal of Biological Chemistry, vol. 277, no. 48, pp. 46116-46122, 2002.

[34] J. P. Eiserich, S. Baldus, M.-L. Brennan et al., "Myeloperoxidase, a leukocyte-derived vascular NO oxidase," Science, vol. 296, no. 5577, pp. 2391-2394, 2002.

[35] D. Schmitt, Z. Shen, R. Zhang et al., "Leukocytes utilize myeloperoxidase-generated nitrating intermediates as physiological catalysts for the generation of biologically active oxidized lipids and sterols in serum," Biochemistry, vol. 38, no. 51, pp. 16904-16915, 1999.

[36] P. J. Randle, P. B. Garland, C. N. Hales, and E. A. Newsholme, "The glucose fatty-acid cycle. Its role in insulin sensitivity and the metabolic disturbances of diabetes mellitus," The Lancet, vol. 281, no. 7285, pp. 785-789, 1963.

[37] A. M. Poynten, S. K. Gan, A. D. Kriketos, L. V. Campbell, and D. J. Chisholm, "Circulating fatty acids, non-high density lipoprotein cholesterol, and insulin-infused fat oxidation acutely influence whole body insulin sensitivity in nondiabetic 
men," Journal of Clinical Endocrinology and Metabolism, vol. 90, no. 2, pp. 1035-1040, 2005.

[38] Y. Azekoshi, T. Yasu, S. Watanabe et al., "Free fatty acid causes leukocyte activation and resultant endothelial dysfunction through enhanced angiotensin II production in mononuclear and polymorphonuclear cells," Hypertension, vol. 56, no. 1, pp. 136-142, 2010.

[39] C. M. Ford, S. Li, and J. G. Pickering, "Angiotensin II stimulates collagen synthesis in human vascular smooth muscle cells: involvement of the AT1 receptor, transforming growth factor$\beta$, and tyrosine phosphorylation," Arteriosclerosis, Thrombosis, and Vascular Biology, vol. 19, no. 8, pp. 1843-1851, 1999.

[40] F. Fakhouri, S. Placier, R. Ardaillou, J.-C. Dussaule, and C. Chatziantoniou, "Angiotensin II activates collagen type I gene in the renal cortex and aorta of transgenic mice through interaction with endothelin and TGF- $\beta$," Journal of the American Society of Nephrology, vol. 12, no. 12, pp. 2701-2710, 2001.

[41] J.-B. Michel, "Renin-angiotensin system and vascular remodelling," Medecine/Sciences, vol. 20, no. 4, pp. 409-413, 2004. 


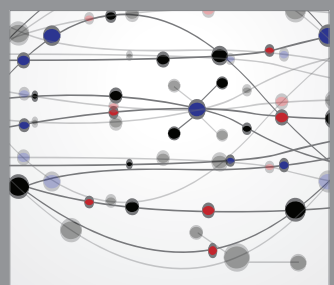

The Scientific World Journal
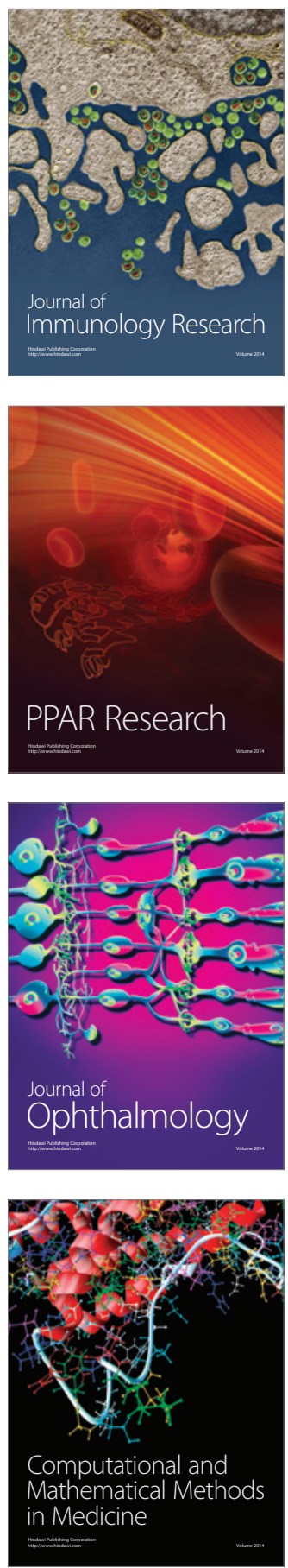

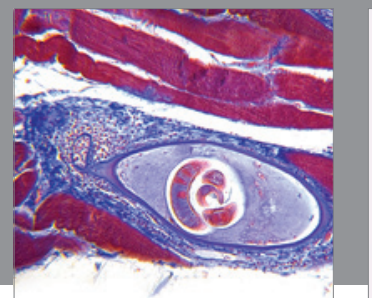

Gastroenterology

Research and Practice
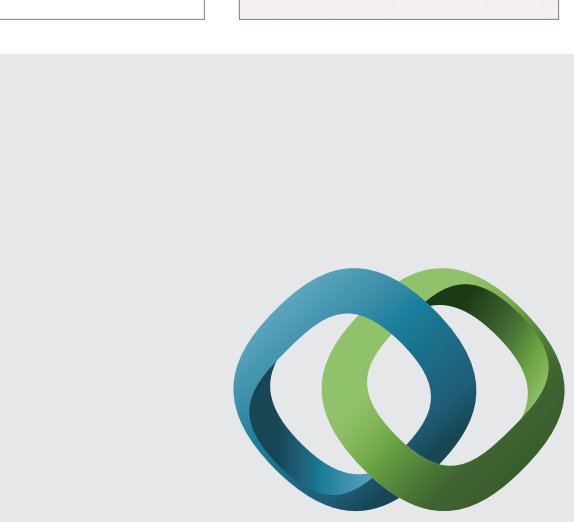

\section{Hindawi}

Submit your manuscripts at

http://www.hindawi.com
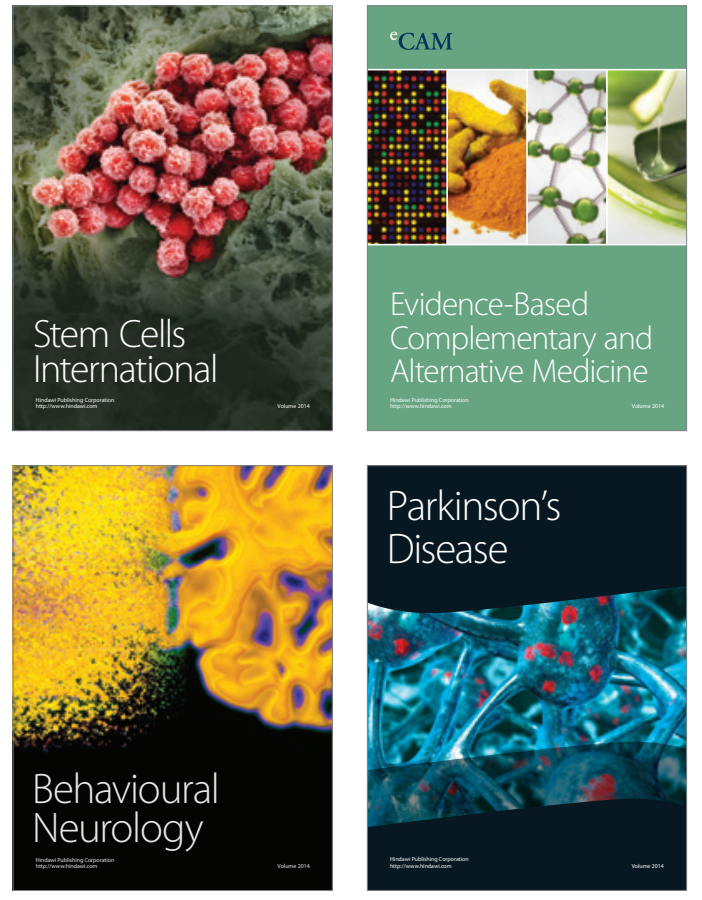
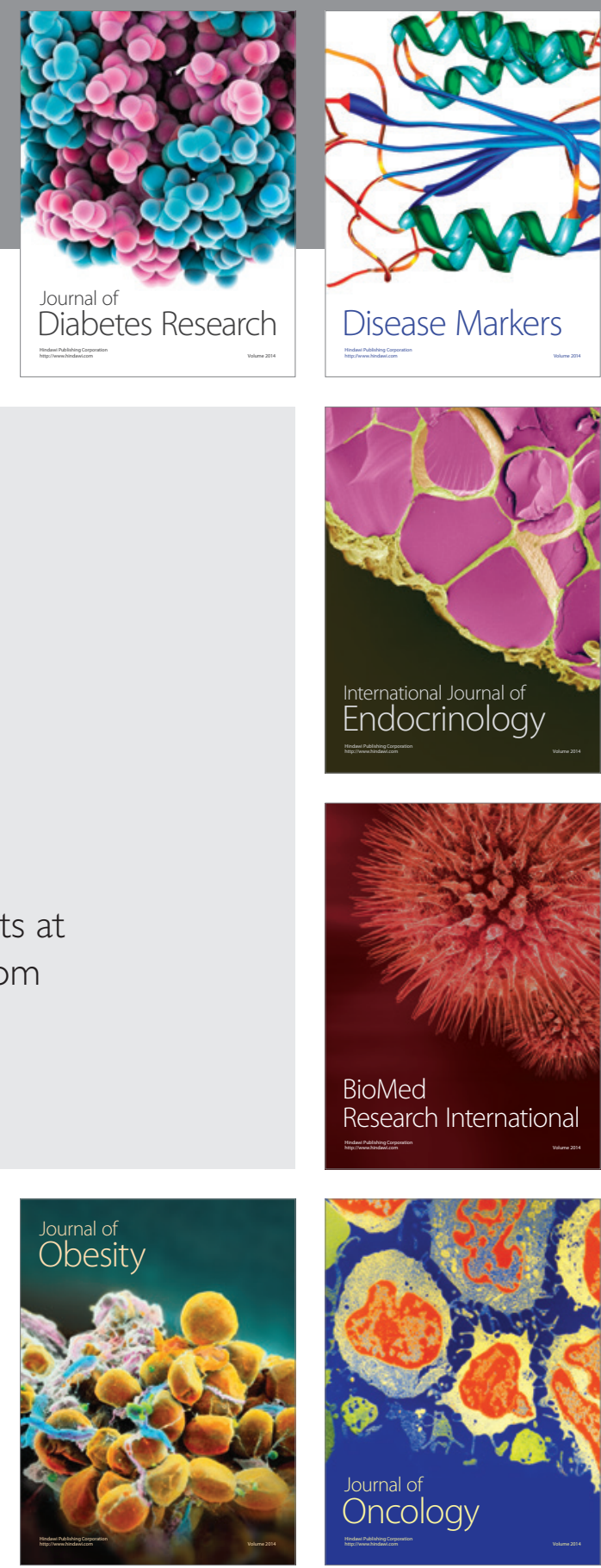

Disease Markers
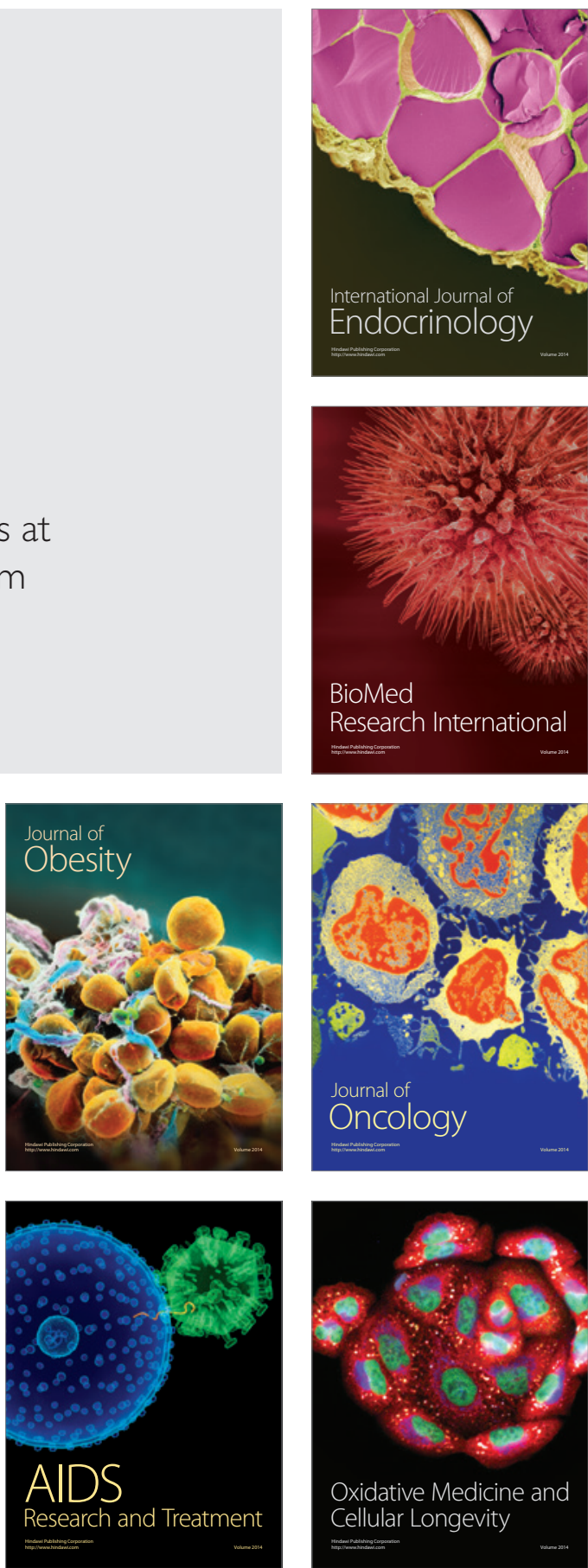